\title{
Chronic Pain and Narcotics
}

\section{A Dilemma for Primary Care}

A ffecting at least 50 million individuals at an annual cost of $\$ 70$ billion, ${ }^{1}$ chronic pain poses a significant health burden in the United States. While therapy for cancer pain has improved dramatically over the past decade, ${ }^{2}$ treatment of nonmalignant chronic pain remains a challenge for many practitioners and patients. Difficulties persist despite an array of medications to treat pain. Narcotics are known to be effective in malignant pain, and are a mainstay in the palliative care of cancer patients. ${ }^{3-9}$ However, narcotic use for nonmalignant chronic pain conditions commonly treated in primary care has been controversial and less well studied.

In this issue of the Journal of General Internal Medicine, Reid et al. ${ }^{10}$ characterize 98 patients receiving narcotic prescriptions for non-cancer-related pain in 2 academic primary care settings in Connecticut. The estimated prevalence of patients with chronic narcotic prescriptions in their study was low, only $0.7 \%$ in a clinic sample and 3\% in a VA sample. Back pain ranked highest among diagnoses for which patients received narcotics, followed by injury-related, non-low back degenerative joint disorders, and diabetic neuropathy. A similar recent study by Adams et al. ${ }^{11}$ in 12 family practice clinics in Wisconsin also noted a low prevalence of narcotic prescriptions for chronic noncancer pain in their overall population, and found the same broad spectrum of painrelated diagnoses. As in previous studies of chronic pain patients, ${ }^{12-14}$ both studies found a considerable amount of psychiatric comorbidity, particularly depression.

Primary care providers' fear of contributing to opiate addiction is a frequently mentioned barrier to narcotic use in the management of chronic pain. While Reid et al. ${ }^{10}$ acknowledge that the criteria they used for assessing prescription drug abuse behavior have limitations, they conclude that "a significant minority (24\% VA and $31 \%$ primary care clinic) of patients had documentation of prescription opioid abuse behavior." Previously reported rates of prescription narcotic abuse, mostly from specialty pain clinics, have ranged from $3 \%$ to $20 \%,{ }^{15,16}$ while Adams et al. ${ }^{11}$ documented an abuse rate of $6 \%$ in their primary care population. Reid et al. ${ }^{10}$ also attempted to identify predictors of prescription drug abuse behavior and noted that a "lifetime history of a substance use disorder" and younger age put patients at higher risk.

As the authors discuss, it is not surprising that chronic pain patients with histories of substance abuse are at higher risk for prescription drug abuse behaviors. While they acknowledge that inadequately treated pain may have been responsible for the higher rates of these behaviors, an important issue not addressed in this study is whether patients gained any pain relief or functional improvement from narcotics. Moreover, given the complex relationships we know exist between substance abuse and mental disorders, ${ }^{17-20}$ and chronic pain syndromes and mental disorders, ${ }^{12-14}$ the knowledge of how prescription drug abuse relates to other substance abuse while controlling for depression would be instructive. While the bivariate relationship between depression and prescription drug abuse did not meet selection criteria for inclusion in Reid et al.'s model of prescription drug abuse $(P<.09)$, it does suggest that depression is related to increased inappropriate use. Information on whether depression was treated, a variable not measured in the study, would also have been informative.

The most revealing findings by Reid et al. concern the types of opioids prescribed for patients with chronic pain. Sixty percent of patients in the VA sample and $46 \%$ of the patients in the primary care clinic sample were given only short-acting opioids. Does this imply less severe pain among these patients? Unlikely, since 88 of the 98 patients in the study were prescribed daily doses of narcotics, while only 10 participants received asneeded doses. According to pain specialists, long-acting opiates should be the mainstay of treatment if narcotics are used for persistent pain. ${ }^{6,21}$ The role of short-acting opioids should be limited to initial dose titration and for breakthrough pain.

These results raise the question of how well primary care physicians are trained in treating chronic pain conditions and, specifically, how well they are informed about prescribing narcotics for these purposes. Attitudinal surveys highlight the ambivalence primary care providers feel about this issue. A survey of 161 family physicians found that while only $2 \%$ of respondents were unwilling to ever prescribe narcotics as needed for patients with noncancer chronic pain, 35\% were unwilling to ever prescribe around-the-clock opioids for these patients, as would be recommended. ${ }^{22} \mathrm{~A}$ national survey of nearly 7,000 physicians in multiple specialties indicated that the negative effects of opioids and concerns over regulatory consequences inhibit many from prescribing narcotics for patients with nonmalignant chronic pain. ${ }^{23}$

To further complicate the issue, there are few widely accepted evidence-based guidelines or consensus statements readily available to help primary care providers manage chronic nonmalignant pain. Since the early 1990s, individual pain researchers and specialty organizations have produced several disease-specific guidelines for this purpose, ${ }^{24-29}$ and in 1997 the American Pain Society issued a broad consensus statement on the use of opioids in the treatment of chronic nonmalignant pain. ${ }^{30}$ However, rather than clarifying the situation, guidelines with differing views on the role of narcotics for these patients have added to the confusion. 
In addition, information on the effectiveness of narcotics in chronic nonmalignant pain largely consists of conflicting observational data, as reviews have shown. ${ }^{1,31,32}$ The few existing randomized trials suggest a benefit from opioids but follow-up is often short, leaving unclear the effects of long-term treatment with these medications. ${ }^{33-40}$ In the absence of clear evidence amidst concerns about the addiction potential of opiates, management of chronic pain patients with narcotics may become susceptible to conscious or unconscious value judgements on the part of providers. Recent reports of abuse of sustained-release Oxycontin ${ }^{41}$ may complicate narcotic treatment decisions even further for primary care physicians. Thus, although the use of opiates has become more accepted in the management of chronic noncancer pain, primary care physicians are often left to rely on their own experience and guesswork, with assistance from pain and other specialties if available.

Reid et al. have added to our understanding of the current use of narcotics for chronic nonmalignant pain in 2 academic primary care settings; their work also underscores what we do not know about chronic noncancer pain in primary care. Little information exists on pain relief and functional outcomes of chronic nonmalignant pain patients treated in primary care, particularly in those receiving narcotics. We have limited knowledge about the long-term benefits and risks of narcotics in chronic pain patients, and multiple questions remain regarding selection of patients for these medications, when to initiate the therapies, and appropriate follow-up. While the potential for prescription drug abuse exists, it is unclear how factors such as comorbid mental health disorders, their treatment, and type of narcotic influence the risk of addiction in this population. Efforts should focus on consolidating management guidelines, and physician education about chronic noncancer pain and narcotics should be systematically incorporated into medical training and continuing medical education. Given the multiple facets of chronic nonmalignant pain, the effectiveness of multidisciplinary approaches to the management of these patients should be formally evaluated as well.

Primary care physicians excel at managing multiple chronic conditions when they have the appropriate tools. For our patients with chronic nonmalignant pain, we hope we will have what it takes. - YNGviLD OLSEN, MD, Division of General Internal Medicine, Johns Hopkins Medical Institutions, Baltimore, Md, and GAIL L. DAUMIT, MD, MHS, Division of General Internal Medicine, Johns Hopkins Medical Institutions and Bloomberg School of Public Health, Baltimore, Md.

\section{REFERENCES}

1. Turk D. Clinicians' attitudes about prolonged use of opioids and the issue of patient heterogeneity. J Pain Symptom Manage. 1996; 11:218-30.

2. Olt GJ. Managing pain and psychological issues in palliative care. Best Pract Res Clin Obstet Gynaecol. 2001;15:235-51.
3. Warfield CA. Controlled-release morphine tablets in patients with chronic cancer pain: a narrative review of controlled clinical trials. Cancer. 1998;82:2299-306.

4. Mercadante S. World Health Organization Guidelines: problem areas in cancer pain management. Cancer Control. 1999;6:191-7.

5. Walsh D. Pharmacological management of cancer pain. Semin Oncol. 2000;27:45-63.

6. Grossman S, Sheidler V. Cancer pain. In: Abeloff MD, ed. Clinical Oncology, $2^{\text {nd }}$ ed. New York: Churchill Livingstone, Inc. 2000; 544-7.

7. American Pain Society Quality of Care Committee. Quality improvement guidelines for the treatment of acute pain and cancer pain. JAMA. 1995;274:1874-80.

8. Working Group of the Ethical Issues in Medicine Committee of the Royal College of Physicians. Principles of pain control in palliative care for adults. Guidance prepared by a Working Group of the Ethical Issues in Medicine Committee of the Royal College of Physicians. J Royal Coll Physicians. 2000;34:350-2.

9. Abrahm JL. Management of pain and spinal cord compression in patients with advanced cancer. ACP-ASIM End-of-life Care Consensus Panel. American College of Physicians-American Society of Internal Medicine. Ann Intern Med. 1999;131:37-46.

10. Reid MC, Engles-Horton LL, Weber MB, Kerns RD, Rogers EL, O'Connor PG. Use of opioid medications for chronic noncancer pain syndromes in primary care. J Gen Intern Med. 2002;17: 173-9.

11. Adams NJ, Plane MB, Fleming MF, Mundt MP, Saunders LA, Stauffacher EA. Opioids and the treatment of chronic pain in a primary care sample. J Pain Symptom Manage. 2001;22:791-6.

12. Fishbain DA, Cutler R, Rosomoff HL, Rosomoff RS. Chronic painassociated depression: antecedent or consequence of chronic pain? A review. Clin J Pain. 1997;13:116-37.

13. Gallagher RM, Verma S. Managing pain and comorbid depression: a public health challenge. Semin Clin Neuropsychiatry. 1999;4: 203-20.

14. Swartz KL, Pratt LA, Armenian HK, Lee LC, Eaton WW. Mental disorders and the incidence of migraine headaches in a community sample: results from the Baltimore Epidemiologic Catchment area follow-up study. Arch Gen Psychiatry. 2000;57:945-50.

15. Fishbain DA, Rosomoff HL, Rosomoff RS. Drug abuse, dependence, and addiction in chronic pain patients. Clin J Pain. 1992; 8:77-85.

16. Aronoff GM. Opioids in chronic pain management: is there a significant risk of addiction? Curr Rev Pain. 2000;4:112-21.

17. Smith LC. Dual diagnosis. Effective recognition and management of severe mental illness and substance abuse. JAAPA 2001;14: 22-4, 27-30, 35-6.

18. Watkins KE, Burnam A, Kung FY, Paddock S. A national survey of care for persons with co-occurring mental and substance abuse disorders. Psychiatr Serv. 2001;52:1062-8.

19. Compton WM III, Cottler LB, Phelps DL, Ben Abdallah A, Spitznagel EL. Psychiatric disorders among drug dependent subjects: are they primary or secondary? Am J Addict. 2000;9: 126-34.

20. Lehman AF, Myers CP, Corty E. Assessment and clarification of patients with psychiatric and substance abuse syndromes. 1989. Psychiatr Serv. 2000; 15:1119-25.

21. McCarberg BH, Barkin RL. Long-acting opioids for chronic pain: pharmacotherapeutic opportunities to enhance compliance, quality of life, and analgesia. Am J Ther. 2001;8:181-6.

22. Potter M, Schafer S, Gonzalez-Mendez E, et al. Opioids for chronic nonmalignant pain. Attitudes and practices of primary care physicians in the UCSF/Stanford Collaborative Research Network. University of California, San Francisco. J Fam Pract. 2001; 50:145-51.

23. Turk DC, Brody MC, Okifuji EA. Physicians' attitudes and practices regarding the long-term prescribing of opioids for noncancer pain. Pain. 1994;59:201-8. 
24. Schofferman J. Long-term use of opioid analgesics for the treatment of chronic pain of nonmalignant origin. J Pain Symptom Manage. 1993;8:279-88.

25. Portenoy RK. Chronic opioid therapy in nonmalignant pain. J Pain Symptom Manage. 1990;5(Suppl 1):46S-62S.

26. Sanders SH, Harden RN, Benson SE, Vicente PJ. Clinical practice guidelines for chronic non-malignant pain syndrome patients II: An evidence-based approach. J Back Musculoskeletal Rehabil. 1999; 13:47-58.

27. Benjamin LJ, Dampier CC, Jacox AK, et al. Guideline for the Management of Acute and Chronic Pain in Sickle-Cell Disease. [APS Clinical Practice Guideline Series No. 1]. Glenview, Ill: American Pain Society; 1999.

28. Practice guidelines for chronic pain management. A report by the American Society of Anesthesiologists Task Force on Pain Management. Chronic Pain Section. Anesthesiology. 1997;86: 995-1004.

29. Hagen N, Flynne P, Hays H, MacDonald N. Guidelines for managing chronic non-malignant pain. Opioids and other agents. College of Physicians and Surgeons of Alberta. Can Fam Physician. 1995;41:49-53.

30. American Academy of Pain Medicine and American Pain Society. The use of opioids for the treatment of chronic pain. A consensus statement. Clin J Pain. 1997;13:6-8.

31. Portenoy R. Opioid therapy for chronic nonmalignant pain: a review of the critical issues. J Pain Symptom Manage. 1996;11: 203-17.

32. Jamison RN. Comprehensive pretreatment and outcome assessment for chronic opioid therapy in nonmalignant pain. $J$ Pain Symptom Manage. 1996;11:231-41.

33. Roth SH, Fleischmann RM, Burch FX, et al. Around-the-clock, controlled-release oxycodone therapy for osteoarthritis-related pain: placebo-controlled trial and long-term evaluation. Arch Intern Med. 2000;160:853-60.

34. Wilder-Smith CH, Hill L, Spargo K, Kalla A. Treatment of severe pain from osteoarthritis with slow-release tramadol or dihydrocodeine in combination with NSAID's: a randomised study comparing analgesia, antinociception and gastrointestinal effects. Pain. 2001;91:23-31.

35. Jamison RN, Raymond SA, Slawsby EA, Nedeljkovic SS, Katz NP. Opioid therapy for chronic noncancer back pain. A randomized prospective study. Spine. 1998;23:2591-600.

36. Allan L, Hays H, Jensen $\mathrm{NH}$, et al. Randomised crossover trial of transdermal fentanyl and sustained release oral morphine for treating chronic non-cancer pain. BMJ. 2001; 322:1154-8.

37. Dellemijn PL, Vanneste JA. Randomised double-blind activeplacebo-controlled crossover trial of intravenous fentanyl in neuropathic pain. Lancet. 1997;349:753-8.

38. Watson CP, Babul N. Efficacy of oxycodone in neuropathic pain: a randomized trial in postherpetic neuralgia. Neurology. 1998;50: 1837-41.

39. Arkinstall W, Sandler A, Goughnour B, Babul N, Harsanyi Z, Darke AC. Efficacy of controlled-release codeine in chronic nonmalignant pain: a randomized, placebo-controlled clinical trial. Pain. 1995;62:169-78.

40. Moulin DE, Iezzi A, Amireh R, Sharpe WK, Boyd D, Merskey H. Randomised trial of oral morphine for chronic non-cancer pain. Lancet. 1996;347:143-7.

41. Tough P. The oxycontin underground: how a prescription painkiller is turning into a pernicious street drug. The New York Times Magazine. July 29, 2001:31-63. 